\title{
A Study of a Binary Liquid-Crystalline Mixtures with the Wide Antiferroelectric Phase
}

\author{
W. PIECEK,${ }^{1, *}$ Z. RASZEWSKI,${ }^{1}$ P. PERKOWSKI,${ }^{1}$ \\ J. KĘDZIERSKI, ${ }^{1}$ J. ZIELIŃSKI, ${ }^{1}$ R. DĄBROWSKI, ${ }^{2}$ \\ S. T. WU, ${ }^{3}$ AND S. GAUZA ${ }^{3}$ \\ ${ }^{1}$ Institute of Applied Physics, Military University of Technology, \\ 00-908 Warsaw, Poland \\ ${ }^{2}$ Institute of Chemistry, Military University of Technology, 00-908 \\ Warsaw, Poland \\ ${ }^{3}$ College of Optics, CREOL, University of Central Florida, Orlando, FL, USA
}

\begin{abstract}
Binary mixtures of fluorinated materials having broad antiferroelectric phase have been prepared. A set of phase parameters (phase transition temperatures and enthalpies, the spontaneous polarization and the tilt angle) of pure antiferroelectric components and mixtures prepared using them have been studied. Electrooptical investigations of obtained mixtures have been conducted. An influence of mole mixing ratio of two components on evolution of electrooptical switching from tristable through V-shaped to $W$-shaped characteristics has been observed. The thresholdless switching of a mixture with specific mixing ratio has been ascribed as the result of the formation of frustrated phase in the medium.
\end{abstract}

Keywords Ferroelectric liquid crystals; antiferroelectric liquid crystals; binary mixtures; tilt angle; spontaneous polarization; V-shaped switching; frustrated phase

\section{Introduction}

It is well known, that ferroelectric (FLC) and antiferroelectric (AFLC) chiral smectic liquid crystals show bistable [1] and tristable [2,3] switching characteristics respectively, giving almost hemispheric viewing angle. Thresholdless, V-shaped switching in various structures of chiral smectic materials has become a subject of extensive investigations due to their very attractive properties for display applications [4], suggesting their potential for active matrix (AM) or thin film transistor (TFT) addressing in display devices [5]. Since now current investigations have been based mainly on the Inui and Mitsui mixtures [6], or mixtures containing achiral swallow-tailed compound and antiferroelectric compounds [7-10]. Known results clearly indicate, that V-shaped switching behavior critically depends on the boundary conditions [11], the thickness of the LC slab and employed frequency of applied electric field. For this kind of the thresholdless behavior of chiral smectic material Inui et al. [12] proposed a Langevin-type switching in a tilted smectic phase with random C-director orientation. However, up till now no clear experimental evidences of

*Corresponding author. E-mail: wpiecek@wat.edu.pl 
such a phase have been observed. In contrary, Seomun et al. [13] have proposed that the tilting randomization due to breaking of the intrinsic inter-layer correlation, resulting in the V-shaped switching.

More recently it has been demonstrated that for materials exhibiting high spontaneous polarization value $\left(\mathrm{P}_{\mathrm{s}} \sim 300\left[\mathrm{nC} / \mathrm{cm}^{2}\right]\right) \mathrm{V}$-shaped switching is largely dominated by electrostatic interactions [14]. On the other hand the thresholdless characteristics exhibited by low polarization materials have been ascribed to specific polarization-director structure. Such a structure called "splayed state" originated from simultaneous action of surfaces and bulk director interactions [14]. However, the role of the molecular structure, molecular shape as well as the role of the materials structure in the sample have not been fully understood yet [4].

Taking the above into account we decided to explore the phenomena of interlayer and intermolecular interactions in binary mixture. To do it, we modified high tilted chiral smectic antiferroelectric material by doping with a similar antiferroelectric compound which would introduce an interlayer and/or intermolecular correlation distortion by its stiff molecular core incompatibility.

A candidate for the mixture basis component (denoted here as component A) has been looked among smectic compounds with antiferroelectric phase existing in a broad temperature range. This broad temperature range of anticlinic phase was chosen to be sure about perfect anticlinic phase stabilization. Such anticlinic materials have been found recently among esters family having partially fluorinated terminal chain [15-19]. Having high optical tilt angle $\theta$ (which in some cases reaches $45^{\circ}$ ) and the phase sequence as follows, $\mathrm{Cr}-\mathrm{SmC}_{\mathrm{A}} *-\mathrm{SmC}^{*}$-SmA $*$-Iso, they exhibit excellent contrast and grey level scale during tristable switching $[20,21]$. As a dopant of our mixture (component B), we decided to use a structural analog having significantly longer molecular rigid core with four phenyl ring system. The influence of mole mixing ratio of two components of the mixture on evolution of electrooptical switching from tristable through V-shaped to $\mathrm{W}$-shaped characteristics has been studied.

\section{Experiment and Results}

Binary mixtures have been prepared using parent compound A (see Fig. 1) and dopant B consisting of a similar molecular elements in the rigid core. Pure $\mathrm{S}$ enantiomers were used. The difference between them is caused only by presence additional - $\mathrm{COO}-\mathrm{Ph}$ - group in

component A

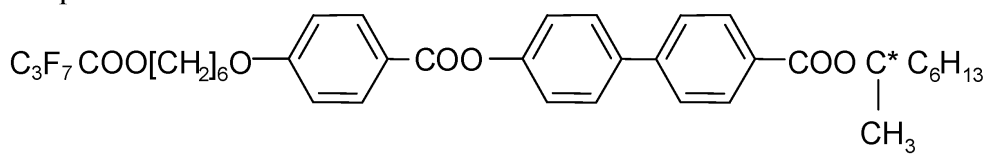

component $\mathrm{B}$

$$
\mathrm{Cr}-18^{\circ} \mathrm{C}-\mathrm{SmC}_{\mathrm{A}} *-98^{\circ} \mathrm{C}-\mathrm{SmC}^{*}-113^{\circ} \mathrm{C} \text {-SmA*-120 }{ }^{\circ} \mathrm{C} \text {-Iso }
$$

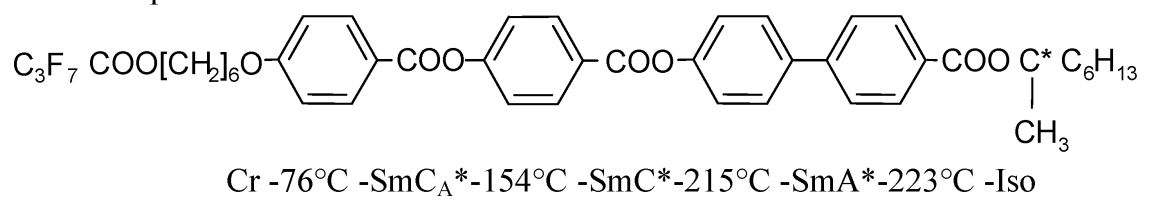

Figure 1. The structure of components $A$ and $B$ of binary mixtures $[\mathrm{AB}]$. 


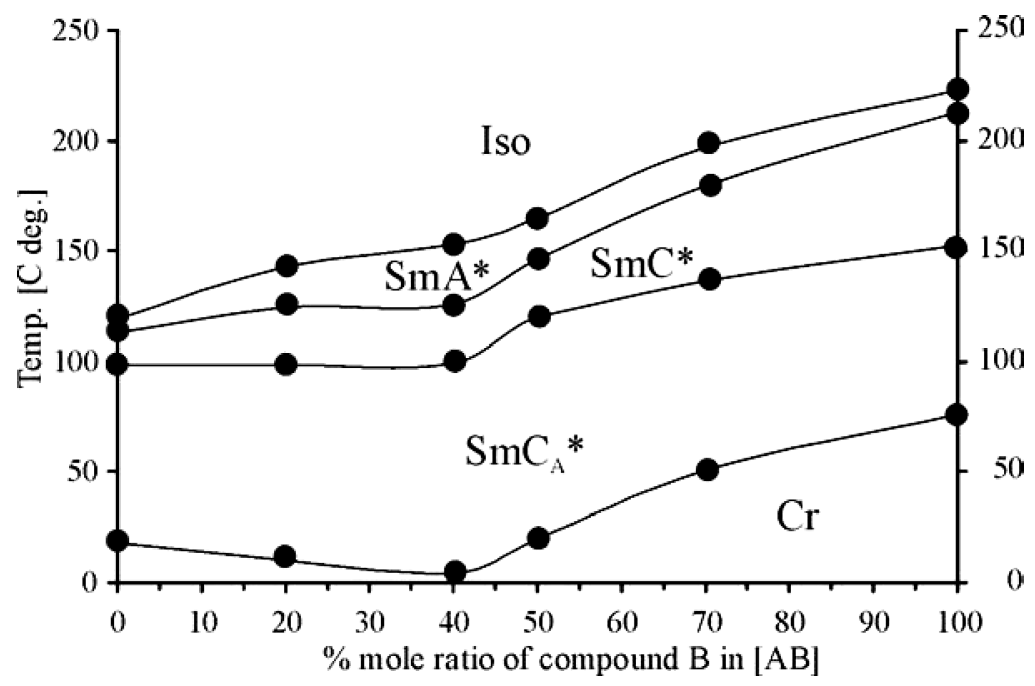

Figure 2. A phase diagram of bicomponent mixture $[\mathrm{AB}]$ obtained by optical inspection using polarizing microscope.

compounds B molecular core. Both parent materials exhibit the same enantiotropic phase sequence.

Prepared mixtures consist of $20 \%, 40 \%, 50 \%$ and $70 \%$ mole fraction of component B in $[\mathrm{AB}]$ mixture.

All phase transitions were investigated by comparison of the texture observation using polarizing optical microscope (BIOLAR-PZO equipped with LINKAM-THMS-600 hot plate) with the traces of electric current switching in thick cells and phase transition heat transfer registered using DSC-SETARAM 141 calorimeter. Results are presented in the Fig. 2 and in Table 1.

\section{Table 1}

Phase transitions temperatures $\mathrm{T}^{\circ} \mathrm{C}$ (upper row) and enthalpies $\Delta \mathrm{H}[\mathrm{kJ} / \mathrm{mol}]$ (lower row) of studied mixtures determined by DSC

\begin{tabular}{lcccc}
\hline $\mathrm{Cr}$ & $\mathrm{SmC}_{\mathrm{A}}{ }^{*}$ & $\mathrm{SmC}^{*}$ & $\mathrm{SmA}^{*}$ & Iso \\
\hline $\mathrm{A}$ & 18 & 98 & 113 & 119 \\
& 2.87 & 0.02 & 0.24 & 1.06 \\
0.2 & 10 & 99 & 129 & 134 \\
& - & - & - & - \\
0.4 & 4.7 & 98.5 & 126 & 155 \\
& - & 0.02 & 0.12 & 0.52 \\
0.5 & 20 & 120 & 147 & 165 \\
& - & - & - & - \\
0.7 & 51 & 121 & 175 & 189.7 \\
& 2.23 & 0.02 & 0.14 & 0.61 \\
$\mathrm{~B}$ & 76 & 154 & 215 & 223 \\
& 5.76 & 0.02 & 0.26 & 0.73 \\
\hline
\end{tabular}


Tilt angle $\theta$ of pure compounds and mixtures has been studied by means of optical switching. For these measurements several sets of uniform thin cells have been prepared. All cells used for the tilt measurements and electrooptical investigations have been cut from the same glass sandwich assembled during the technology process. For cell preparation we used glass for TN technology. One side of the glass substrate was covered by ITO layer. During photolitography process electrodes of area $25\left[\mathrm{~mm}^{2}\right]$ were produced. Glass plates have been covered with about 300 angstroms of "Du Pont PI 2610" polyimide layer by spin coating. Then substrates were dried and cured in hot chamber at high temperature. Glass plates, being antiparallel rubbed, were assembled. Glass microrods were used as a spacer. Such assembled substrates were next cut for single measuring cells. Cells gap was in range of $1.7 \pm 0.1[\mu \mathrm{m}]$ according to combined tests incorporating interferometric and dielectric inspection methods. Cells have been filled with examined materials by capillary action in the isotropic phase and subsequently they have been conditioned by slow cooling $(0.05[\mathrm{~K} / \mathrm{min}])$ on a hot plate in the presence of external low frequency, AC electric field (frequency $\mathrm{f}=15[\mathrm{~Hz}]$, electric filed strength $\mathrm{E} \approx 5[\mathrm{~V} / \mu \mathrm{m}]$ ) generated by FLC Electronics WFG 500 waveform generator. During the tilt measurements all cells were placed between crossed polarizers and driven using square shape driving pulse. The electrooptical switching has been observed using FLC Electronics PIN 20 silicon photodiode connected to an HP 54601B digital storage oscilloscope and PC. The results of the tilt angle measurements are presented in the Fig. 3.

The spontaneous polarization $\mathrm{P}_{\mathrm{s}}$ of studied mixtures has been measured in 4.8 micron cells by means of reversal current method for triangle shape driving pulses. All cells used for this purpose have been prepared in the way described above. Results of measurements are given in the Fig. 4.

Hysteresis loops have been registered for the same samples as used for the tilt angle investigations. The optical response of the sample placed in the birefractive set-up and driven with the triangle voltage pulse of frequency from $0.01 \mathrm{~Hz}$ to $20 \mathrm{~Hz}$ was recorded. The amplitude of the electric field was adjusted to saturate the switching. Results were collected for samples conditioned during a few minutes continuous driving. Switching characteristics

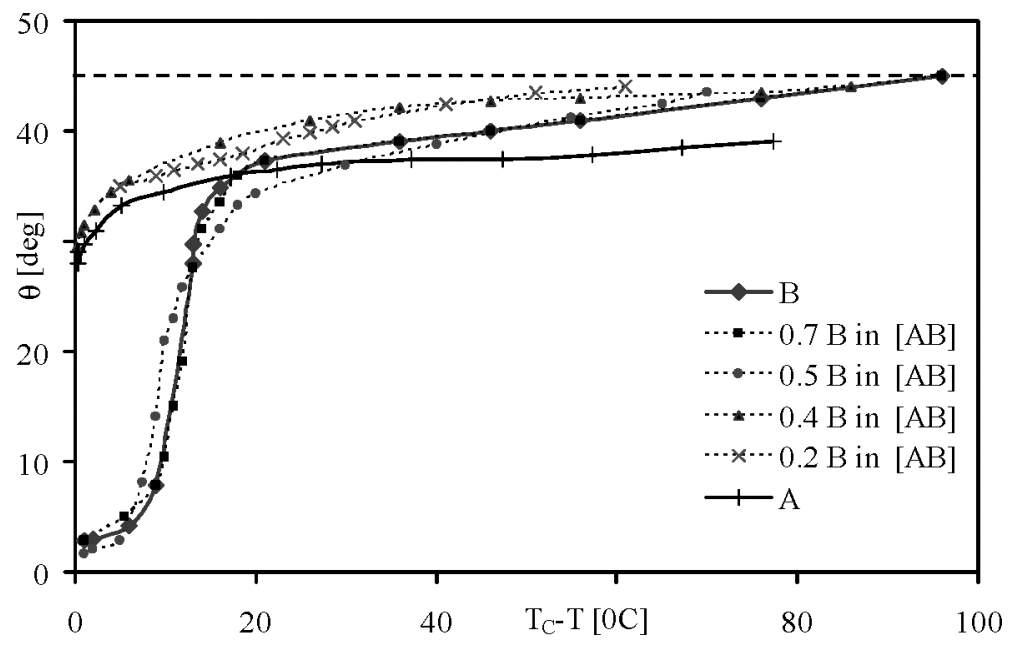

Figure 3. The tilt angle $\theta$ vs. reduced temperature $\mathrm{T}_{\mathrm{c}}-\mathrm{T}$ for studied mixtures $[\mathrm{AB}]$. (See Color Plate XVI) 


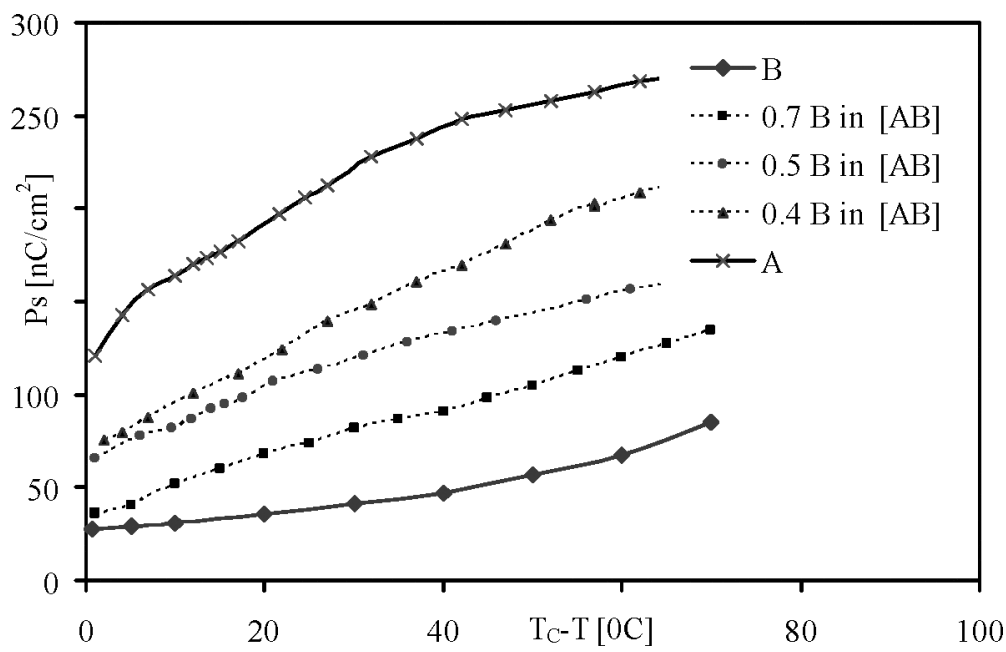

Figure 4. The spontaneous polarization $P_{s}$ vs. reduced temperature $T_{c}-T$ for studied mixtures $[A B]$. (See Color Plate XVII)

of pure compounds and mixtures $[\mathrm{AB}]$ with different mixing ratio are presented in the Fig. 5.

Broad temperature and relatively wide frequency ranges of V-shaped switching characteristics was detected using cells filled with the mixture containing 0.7 mole fraction of compound $\mathrm{B}$ in $[\mathrm{AB}]$ mixture (see Table 2 and Figure 6). The change of switching
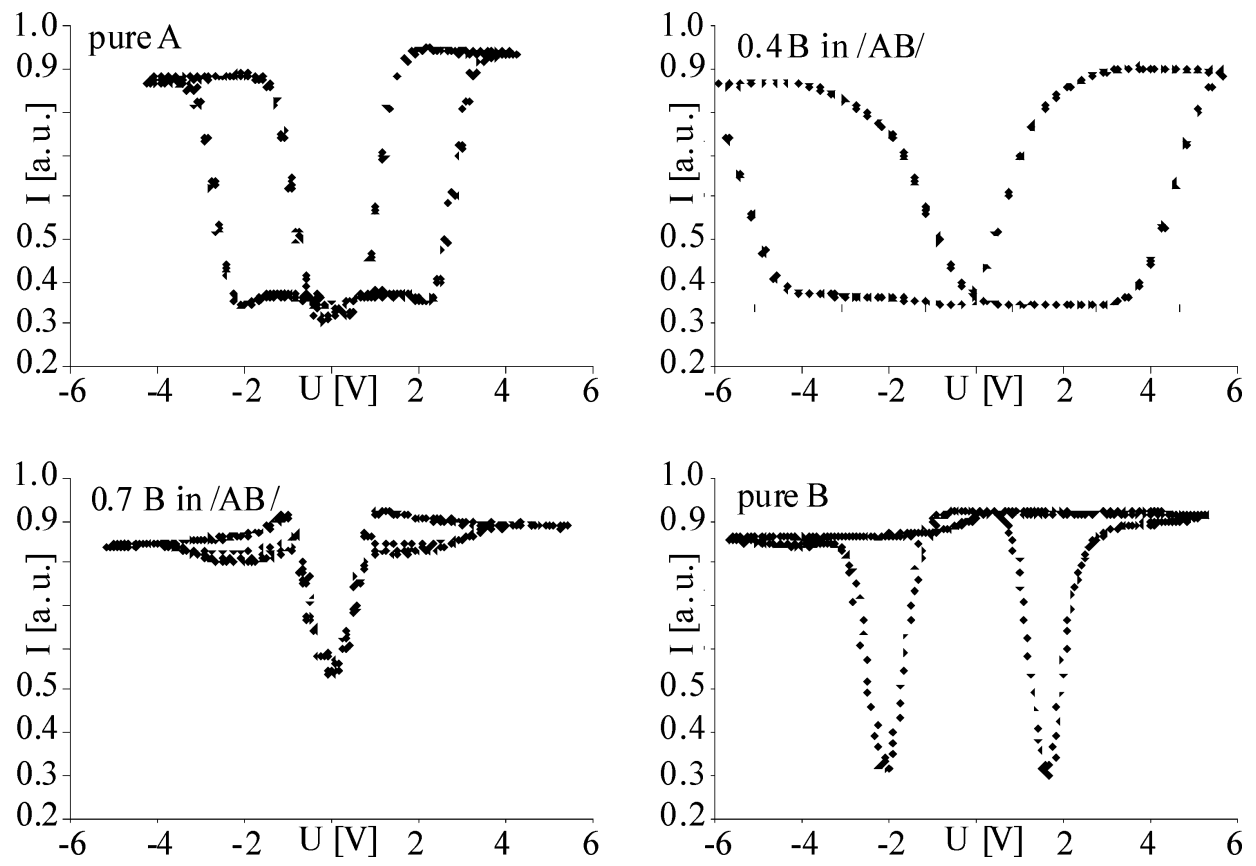

Figure 5. A transmitted light intensity I[a.u.] vs. voltage U[V]. All characteristics were taken in the tilted phase at reduced temp. of $\mathrm{Tc}_{\mathrm{A}}-\mathrm{T}=10^{\circ} \mathrm{C}$ and frequency of $0.1[\mathrm{~Hz}]$. 
Table 2

Switching characteristics vs. temperature and electric field frequency applied. "V" and "W" stand for V-shaped and W-shaped switching respectively

\begin{tabular}{|c|c|c|c|c|}
\hline Temp. & $\mathrm{U} / 1.7[\mu \mathrm{m}]$ & $0,03[\mathrm{~Hz}]$ & $0,1[\mathrm{~Hz}]$ & $1[\mathrm{~Hz}]$ \\
\hline \multirow[t]{5}{*}{$160\left[{ }^{\circ} \mathrm{C}\right]$} & $20.0 \mathrm{~V}_{\mathrm{pp}}$ & $\mathrm{V}$ & $\mathrm{W}$ & W \\
\hline & $15.0 \mathrm{~V}_{\mathrm{pp}}$ & $\mathrm{V}$ & $\mathrm{W}$ & $\mathrm{W}$ \\
\hline & $10.0 \mathrm{~V}_{\mathrm{pp}}$ & $\mathrm{V}$ & W & $\mathrm{W}$ \\
\hline & $7.5 \mathrm{~V}_{\mathrm{pp}}$ & V & W & $\mathrm{V}$ \\
\hline & $4.0 \mathrm{~V}_{\mathrm{pp}}$ & $\mathrm{W}$ & $\mathrm{W}$ & $\mathrm{V}$ \\
\hline \multirow[t]{5}{*}{$150\left[{ }^{\circ} \mathrm{C}\right]$} & $20.0 \mathrm{~V}_{\mathrm{pp}}$ & V & V & $\mathrm{W}$ \\
\hline & $15.0 \mathrm{~V}_{\mathrm{pp}}$ & V & V & $\mathrm{W}$ \\
\hline & $10.0 \mathrm{~V}_{\mathrm{pp}}$ & $\mathrm{V}$ & V & $\mathrm{W}$ \\
\hline & $7.5 \mathrm{~V}_{\mathrm{pp}}$ & $\mathrm{V}$ & $\mathrm{V}$ & W \\
\hline & $4.0 \mathrm{~V}_{\mathrm{pp}}$ & $\mathrm{W}$ & V & $\mathrm{W}$ \\
\hline \multirow[t]{5}{*}{$140\left[{ }^{\circ} \mathrm{C}\right]$} & $20.0 \mathrm{~V}_{\mathrm{pp}}$ & V & V & $\mathrm{V}$ \\
\hline & $15.0 \mathrm{~V}_{\mathrm{pp}}$ & V & V & $\mathrm{V}$ \\
\hline & $10.0 \mathrm{~V}_{\mathrm{pp}}$ & $\mathrm{V}$ & $\mathrm{V}$ & $\mathrm{V}$ \\
\hline & $7.5 \mathrm{~V}_{\mathrm{pp}}$ & V & $\mathrm{W}$ & $\mathrm{V}$ \\
\hline & $4.0 \mathrm{~V}_{\mathrm{pp}}$ & $\mathrm{W}$ & $\mathrm{W}$ & $\mathrm{V}$ \\
\hline \multirow[t]{5}{*}{$130\left[{ }^{\circ} \mathrm{C}\right]$} & $20.0 \mathrm{~V}_{\mathrm{pp}}$ & V & V & V \\
\hline & $15.0 \mathrm{~V}_{\mathrm{pp}}$ & V & V & $\mathrm{V}$ \\
\hline & $10.0 \mathrm{~V}_{\mathrm{pp}}$ & $\mathrm{V}$ & V & $\mathrm{W}$ \\
\hline & $7.5 \mathrm{~V}_{\mathrm{pp}}$ & $\mathrm{W}$ & V & $\mathrm{W}$ \\
\hline & $4.0 \mathrm{~V}_{\mathrm{pp}}$ & W & W & W \\
\hline \multirow[t]{5}{*}{$120\left[{ }^{\circ} \mathrm{C}\right]$} & $20.0 \mathrm{~V}_{\mathrm{pp}}$ & $\mathrm{V}$ & $\mathrm{V}$ & $\mathrm{W}$ \\
\hline & $15.0 \mathrm{~V}_{\mathrm{pp}}$ & V & V & W \\
\hline & $10.0 \mathrm{~V}_{\mathrm{pp}}$ & V & V & $\mathrm{W}$ \\
\hline & $7.5 \mathrm{~V}_{\mathrm{pp}}$ & $\mathrm{W}$ & V & $\mathrm{W}$ \\
\hline & $4.0 \mathrm{~V}_{\mathrm{pp}}$ & W & $\mathrm{W}$ & $\mathrm{W}$ \\
\hline
\end{tabular}

characteristics from tristable through thresholdless to $\mathrm{W}$-shaped has been observed upon compounds $\mathrm{B}$ concentration in $[\mathrm{AB}]$ mixture.

\section{Discussion And Conclusions}

One can see that obtained mixtures maintained phase sequence of pure components and exhibit wide temperature range of anticlinic phase too. It is worth to note, that the compounds

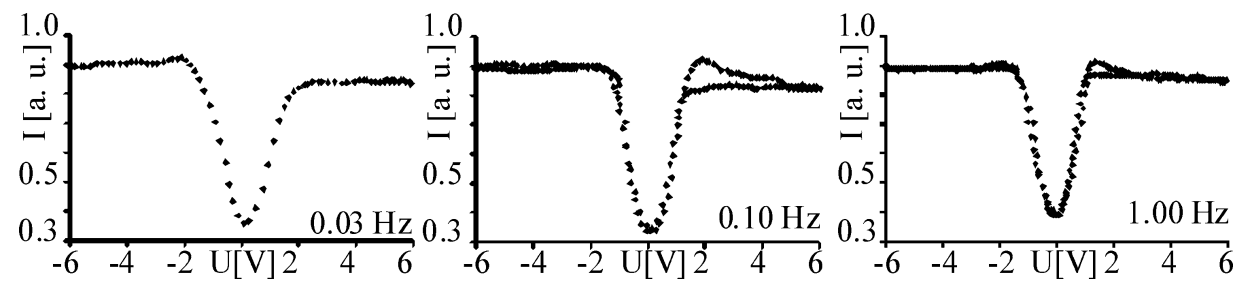

Figure 6. Transmitted light intensity I[a.u.] vs. applied voltage $\mathrm{U}[\mathrm{V}]$ for the mixture $0.7 \mathrm{~B}$ in $[\mathrm{AB}]$ at the temp. of $130^{\circ} \mathrm{C}$ for driving pulse $15\left[\mathrm{~V}_{\mathrm{pp}}\right]$ at frequency $0.03[\mathrm{~Hz}], 0.10[\mathrm{~Hz}]$ and $1.00[\mathrm{~Hz}]$ respectively. 
A and B show different temperature characteristics of the tilt angle and spontaneous polarization. Compound A exhibits de Vries like behavior (see Fig. 3) described elsewhere [22, 23 ] while the compound $B$ exhibits regular behavior. Mixture $[A B]$ consisting of compound $\mathrm{B}$ in amount below 0.4 mole ratio resemble behavior of compound A while the mixture comprising compound $\mathrm{B}$ in amount higher than 0.4 mole ratio resembles properties of compound B. Upon the increasing of the above mole fraction of compound $B$ in the mixture $[A B]$ de Vries like behavior disappears. Moreover, upon the increase of mole fraction of compound $B$ in the mixture $[A B]$ the saturated value of the tilt angle increases and for studied mixtures and is higher than for pure compounds. For all mixtures the tilt angle saturates at angle of $43^{\circ}-45^{\circ}$ depending of the mixture. Hence, all mixtures can be regarded as orthoconic-like materials. This observation suggests that the molecular core of compound B strongly supports forming of high tilted phase of the three ring compound A. The above is in opposition to two ring structural analogs which are considered to cause the tilt angle drop [21].

As one can see in the Table 1 a presence of molecules of compound $\mathrm{B}$ in mixture [AB] leads to significant lowering of enthalpy for the phase transition from orthogonal to tilted phase. This observation suggests that in this case we may have a frustrated phase [24] -less ordered than compound $\mathrm{B}$, although the enthalpy of $\mathrm{SmC}_{A}-\mathrm{SmC}$ phase transition is kept constant. Most important is an observation that material B (which exhibit an electrooptical effect with W-shaped threshold voltage ascribed to surface-stabilized FLC structure) in mixture with shorter molecules of compound A changes its characteristics to a thresholdless. It takes place for the mixture comprising of 0.7 mole ratio of $\mathrm{B}$ in [AB]. It looks to be consistent with earlier observations that thresholdless switching of AFLC phase appears for certain composition of compounds only [12,25].

On the basis of the theoretical prediction given by Parry-Jones et al. [26, 27] we assume that changing molar mixing ratio we have changed, among the others, interlayer interaction energy. According to the theoretical model mentioned above, upon a change of the ratio $\Delta / \Gamma$ (where $\Gamma$ stands for dipolar and $\Delta$ stands for quadrupolar components of the interlayer interaction energy respectively) the switching characteristics changes. When the ratio is $\Delta / \Gamma<0.05$ thresholdless characteristic is observed, while the system exhibits hysteresis for the ratio $\Delta / \Gamma>0.05$. In case of mixtures $[\mathrm{AB}]$ the interlayer correlation were possibly distorted by molecular rigid cores incompatibility what resulted in the change of switching characteristics in thin samples (Fig. 5) from AFLC switching for pure compound A, through thresholdless switching in the mixture $0.7 \mathrm{~B}$ in $[\mathrm{AB}]$ to SSFLC-like, W-shaped switching of pure compound B. Four ring compound B is probably very viscous, what prevents fast relaxation to antiferroelectric state and is exists in ferroelectric state in surface stabilized conditions. Obtained switching characteristics upon mixing ratio and above theoretical prediction indicates that possibly quadrupolar factor of interlayer interactions for compound $\mathrm{B}$ are stronger than those for compound A. We assume that the above appears for the same boundary conditions.

To summarize above considerations we suggest that the best way for obtaining efficient working thresholdless orthoconic AFLC material goes through composition of mixtures with frustrated anticlinic phase where both ferroelectric and antiferroelectric states are possible and a specific ratio between dipolar and quadrupolar interactions is achieved.

\section{Acknowledgment}

This work was supported by the Polish Ministry of Scientific Research and Information Technology in years 2003-2006 (grant No. 0 T00C 006 25) and NATO Program Security Through Science, Collaborative Linkage Grant, No. CBP.EAP.CLG 981323. 


\section{References}

1. N. A. Clark and S. T. Lagerwall, Applied Physics Letters 36, 889 (1980).

2. A. D. L. Chandani, T. Hagiwara, Y. Suzuki, Y. Ouchi, H. Takezoe. and A. Fukuda, Japanese Journal of Applied Physics 27, L1265 (1988).

3. A. D. L. Chandani, E. Górecka, Y. Ouchi, H. Takezoe, and A. Fukuda, Japanese Journal of Applied Physics 27, L729 (1989).

4. S. T. Lagerwall, Ferroelectrics 301, 15 (2004).

5. T. Saishu, K. Takatoh, R. Iida, H. Nagata, and Y. Mori, SID 96 DIGEST 28.4, (1997).

6. S.-S. Seomun, T. Gouda, O. Takanishi, K. Ishikawa, and H. Takezoe, Liquid Crystals 26(2), 151 (1999).

7. S.-L. Wu and C.-T. Ciang, Liquid Crystals 29(1), 39 (2002).

8. S.-L. Wu and C.-Y. lin, Liquid Crystals 30 (2), 205 (2003).

9. R. Dabrowski, J. Gasowska, M. Filipowicz, J. Przedmojski, M. Tykarska, J. Otón, Manuel, P. Castillo, and N. Benis, School on Chiral Liquid Crystals Bedlewo, Poland (2005).

10. P. Kula, M. Tykarska, and K. Skrzypek, School of Chiral Liquid Crystals, Bedlewo, Poland (2005).

11. A. D. L. Chandani, Y. Cui, S.-S. Seomun, Y. Takanishi, K. Ishikawa, H. Takezoe, and A. Fukuda, Liquid Crystals 26(2), 167 (1999).

12. S. Inui, N. Iimura, T. Suzuki, H. Iwane, K. Miyachi, Y. Takanishi, and A. Fukuda, Journal of Materials Chemistry 6(4), 671 (1996).

13. S. S. Seomun, Y. Takanishi, K. Ishikawa, H. Takezoe, A. Fukuda, C. Tanaka, T. Fujiyama, T. Maruyama, and S. Nishiyama, Molecular Crystals and Liquid Crystals Science and Technology Section A: Molecular Crystals and Liquid Crystals 303, 181 (1997).

14. N. A. Clark, D. Coleman, and J. E. Maclennan, Liquid Crystals 27(7), 985 (2000).

15. R. Dabrowski, Ferroelectrics 243, 1 (2000).

16. W. Drzewinski, K. Czuprynski, R. Dabrowski, and M. Neubert, Molecular Crystals and Liquid Crystals Science and Technology Section A: Molecular Crystals and Liquid Crystals 328, 401 (1999).

17. W. Drzewinski, R. Dabrowski, and K. Czuprynski, Polish Journal of Chemistry 76 (2-3), 273 (2002).

18. J. Gasowska, R. Dabrowski, W. Drzewinski, K. Kenig, M. Tykarska, and J. Przedmojski, Molecular Crystals and Liquid Crystals 411, (2004).

19. R. Dabrowski, J. Gasowska, J. Otón, W. Piecek, J. Przedmojski, and M. Tykarska, Display 25, 9 (2004).

20. K. D'have, P. Rudquist, M. Matuszczyk, S. T. Lagerwall, H. Pauwels, and R. Dabrowski, SPIE 3955, 33 (2000).

21. R. Dabrowski, K. Czuprynski, W. Drzewinski, S. Gauza, S. T. Lagerwall, and P. Rudquist, SID 2002 DIGEST 770 (2002).

22. W. Piecek, Z. Raszewski, P. Perkowski, J. Kedzierski, J. Rutkowska, J. Zielinski, E. NowinowskiKruszelnicki, R. Dabrowski, M. Tykarska, and J. Przedmojski, Molecular Crystals and Liquid Crystals 436, 149/[1103] (2005).

23. J. P. F. Lagerwall, A. Saipa, F. Giesselmann, and R. Dabrowski, Liquid Crystals 31 (00), 1 (2004).

24. J. W. Goodby, A. J. Slaney, C. J. Booth, I. Nishiyama, D. J. Vuijk, P. Styring, and K. J. Toyne, Molecular Crystals and Liquid Crystals 224, 231 (1994).

25. A. Fukuda, Digest of Asia Display'95 S6-1, 61 (1995).

26. L. A. Parry-Jones and S. J. Elston, Applied Physics Letters 79 (13), 2097 (2001).

27. L. A. Parry-Jones and S. J. Elston, Molecular Crystals and Liquid Crystals 410, 141 (2004). 